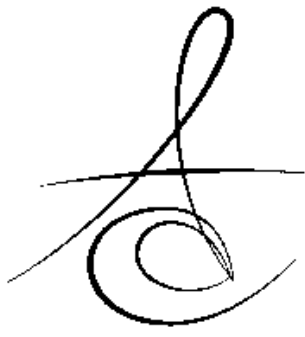

Makale Kodu/Article code: 2083

Makale Gönderilme tarihi: 27.01.2015

Kabul Tarihi: 03.04.2015

\section{FARKLI İÇECEKLERİN REZİN ESASLI RESTORATİF MATERYALLERİN RENKLEŞMESİ ÜZERİNE ETKİSİ}

\section{THE EFFECTS OF DIFFERENT BEVERAGES ON STAINING OF RESIN BASED RESTORATIVE MATERIALS}

\author{
Arş. Gör. Dt. Başak BÖLÜKBAŞI* $\quad$ Arş. Gör. Dt. Süeda KARA* \\ Doç. Dr. Dilşah çoĞULU **
}

\section{ÖZET}

Estetik dental restorasyonların başarısında en önemli kriterlerden birisi doğal diş ile restorasyon materyali arasındaki renk uyumudur. Ağız ortamında rezin kompozitlerin renkleşmeye olan eğilimleri, estetik problemler ortaya çıkartarak restorasyonların yenilenmesini gerektirmekte, bu durum da hasta ve hekim için hem zaman hem de maddi kayba yol açmaktadır. Restoratif materyalin özellikleri, beslenme alışkanlıkları gibi faktörler renkleşmeyi önemli ölçüde etkilemektedir. Bu derlemenin amacı rezin kompozit materyallerin, farklı içecekler tarafından renkleşmesini etkileyen faktörlerin incelenmesidir. renkleşme

Anahtar Kelimeler: Rezin kompozit, içecek,

\section{GİRİş}

Rezin esaslı restoratif materyaller, geliştirilmiş estetik ve fiziksel özellikleri nedeniyle ön ve arka bölgedeki dental restorasyonlarda sıklıkla tercih edilmektedir. ${ }^{1}$ Estetik restoratif materyaller, diş dokusu ile renk uyumu sağlayarak doğal diş görünümünü taklit edebilmeli ve ağızda kaldığı süre boyunca bu özelliğini koruyabilmelidir. ${ }^{2,3}$ Ağız ortamında rezin kompozitlerin renkleşmeye olan eğilimleri estetik problemler ortaya çıkarmaktadır. Materyalin renkleşmesi sonucu oluşan kötü estetik görünümün giderilmesi amacıyla restorasyonların yenilenmesi gerekmekte, bu durum da hasta ve hekim için hem zaman hem da maddi kayıp oluşturmaktadır. $^{4}$

Dental materyallerde oluşan renkleşme, spektrofotometre ve kolorimetre gibi çeşitli araçlarla ölçülebilmektedir. ${ }^{5,6}$ Bu şekilde tekrarlanabilir objektif

\section{ABSTRACT}

One of the most important criteria for the success of dental restorations is an esthetic harmony between the natural tooth color and restorative materials. The affinity of the staining of resin composites in the oral environment requires the renewal of the restorations and this situation leads to loss of time and material for both patients and dentists. Characteristics of the restorative material, dietary habits are important factors in staining of restoration. The purpose of this review is to inform the readers about the effects of different beverages on the staining of composite resin materials.

Key Words: Resin composite, beverage, discoloration

ölçümler sağlanmakta ve gözle ayırt edilemeyen renk değişimleri belirlenebilmektedir. ${ }^{6}$ Spektrofotometre, diş rengini CIELab renk sistemini kullanarak ölçmektedir. Renk değişimi $\Delta \mathrm{E}$ adı verilen değerle ifade edilmektedir. Estetik restorasyonlardaki renk değişimini değerlendirmek için üç değer aralığı kullanılmaktadır. $\Delta \mathrm{E}<1$; insan gözü ile ayırt edilemeyecek renk değişimi olduğunu, $1<\Delta \mathrm{E}<3,7$; uzman bir göz tarafından ayırt edilebilecek renk değişimini belirtmekte ve klinik olarak kabul edilebilmektedir. $\Delta \mathrm{E}>3,7$ ise kolaylıkla gözle görülebilen ve klinik olarak kabul edilemez bir renk değişimi olarak değerlendirilmektedir. ${ }^{7}$

Gelişen teknoloji ile birlikte farklı materyaller üretilmesine rağmen materyallerin renkleşmesi uzun süreli klinik başarı için problem oluşturmaya devam etmektedir. ${ }^{8}$ Renkleşme, rezin materyal ve renklendirici ajan arasındaki etkileşim ile oluşmaktadır. ${ }^{9}$ Rezin materyallerin renk değişimlerinde dışsal ve içsel faktörler

\footnotetext{
*i̇zmir Katip Çelebi Üniversitesi, Diş Hekimliği Fakültesi, Pedodonti Anabilim Dalı

${ }^{* *}$ Ege Üniversitesi, Diş Hekimliği Fakültesi, Pedodonti Anabilim Dalı
} 
rol oynamaktadır. ${ }^{10}$ Renk değişim miktarı; materyalin polimerizasyon şekli, doldurucu tipi, su emilimi, kimyasal reaksiyon, diyet, sigara içme alışkanlığı, kötü oral hijyen ve yüzey pürüzlülüğü gibi faktörlerden etkilenmektedir. ${ }^{11,12}$ Çalışmalar, polimerize olmuş materyallerde, su emilimine bağlı intrensek faktörlerle oluşan renklenmenin çok az olduğunu, renklendirici pigment içeren diyet ve kimyasal boyayıc ajanlarla oluşan renklenmenin ise belirgin boyutta olduğunu göstermektedir. ${ }^{13}$

$\mathrm{Bu}$ derlemenin amacl rezin kompozit materyallerin, farklı içecekler tarafından renkleşmesini etkileyen faktörlerin incelenmesidir.

\section{Alınan içeceklere ait özellikler}

Yapılan bir çalışmada içeceklerin içerdikleri pigment miktarına bağlı olarak klinik olarak kabul edilemeyecek ve restorasyonların değişimini gerektirecek renk değişimi oluşturduğu belirlenmiştir. ${ }^{14}$

Dental materyallerin renkleşmesinde diyetle alınan pigment içerikli gıdalar absorbsiyon ve adsorbsiyona bağlı olarak renkleşme oluşturmaktadır. ${ }^{15}$ Yapılan çalışmalar rezin bazlı kompozitlerin yaygın olarak tüketilen çay, kahve, kola, kırmızı şarap, meyve suları, enerji içecekleri gibi renklendirici pigment içeren içeceklerden etkilenerek renkleşme oluşturduklarını göstermektedir. ${ }^{13,14,16}$ Yaban mersini, kırmızı üzüm, kırmızı şarap gibi antioksidan içerikli içeceklerin daha fazla renk değişimi oluşturdukları belirlenmiştir. ${ }^{17}$

Ayrıca içeceğin türü, içerdiği pigment miktarı, $\mathrm{pH}$ değeri gibi faktörlerin farklı derecelerde renkleşmelere neden olduğu tespit edilmiştir. ${ }^{17}$ Düşük $\mathrm{pH}$ ve alkol içeriğinin kompozit rezinlerin yüzey özelliklerini etkilediği belirtilmiştir. ${ }^{18}$ İçeceklerdeki alkol moleküllerinin rezin matriks içerisine emilimi, kompozit yüzeyinde yumuşamaya sebep olmakta, yüzey pürüzlülüğü ve pigmentlerin tutunması için yüzey alanını arttırmakta ve böylece daha fazla renkleşme oluşmaktadır. ${ }^{19}$ Yapılan bir çalışmada üzüm suyunun düşük $\mathrm{pH}^{\prime}$ sının kompozit rezinin yüzey özelliklerini etkilediği ve pigment tutulumunu arttırdığı gözlenmiştir. ${ }^{14}$

Güler ve arkadaşları içeceklerdeki şeker varlığının, renklendirici pigmentlerin yapışmasını kolaylaştırdığını ve buna bağlı olarak kompozit restoratif materyallerin renkleşmesini arttırdığını belirtmektedir. ${ }^{20}$

\section{Rezin materyale ait özellikler}

Kompozit rezinin matriksi, doldurucu tipi, matriks yüzeyi ve yetersiz polimerizasyonu gibi faktörler renk stabilitesini önemli ölçüde etkilemektedir. ${ }^{21,22}$ Bu durum rezin matriksin çözünebilirliğine ve doldurucu rezin bağlantısının kimyasal dejenerasyonuna bağlı oluşabilmektedir. ${ }^{22}$ Materyal içerisine su emilimi rezin matriksin yumuşamasına, rezinin bozulmasına ve renkleşmeye karşı direncin azalmasına neden olabilmektedir. ${ }^{23}$ Kimyasal renk değişimi, amin hızlandırıcının oksidasyonuna ya da değişimine, polimer matriks yapısındaki oksidasyona ve reaksiyona girmemiş metakrilat zincir gruplarının oksidasyonuna bağlı oluşabilmektedir. ${ }^{24}$

Rezin materyallerin içeriği, doldurucu partikül özellikleri ve polimerizasyon tipleri renkleşmede önemli rol oynamaktadır. ${ }^{21}$ Rezin matriksin hidrofilik özelliği ve su emilim derecesi rezin kompozitlerin renkleşmelerini etkilemektedir. Rezin kompozit, su emilimi yapabiliyorsa renkleşmeye neden olabilecek diğer sıvıların emilimini de yapabiliyor demektir. ${ }^{25}$ Su emilimi direkt olarak rezin matriksin içerisine doğru oluşmaktadır. Rezin kompozit materyali içerisine su emilimi, rezin komponentin genleşmesine ve plastize olmasına, silanın hidrolizine ve mikrokırık oluşumuna neden olabilmektedir. Sonuçta mikrokırıklar ve doldurucumatriks arasındaki boşluklar renklendirici ajanların penetrasyonuna ve renk değişimine neden olmaktadır. Rezin matriks ortamdaki suyu absorblamasına rağmen inorganik doldurucu materyalin kütlesine su emilimi yapmaz, sadece kendi etrafındaki suyu absorbe eder. ${ }^{26}$

Üretan dimetakrilat (UDMA) bazlı monomerler diğer dimetakrilat bazlı monomer tiplerine göre daha az renkleşme göstermektedir. Bu durumun UDMA'nın düşük miktarda su absorbsiyon özelliğinin olmasına, düşük viskozitesine ve görünür ışıkla kolayca polimerize olmasına bağlı olduğu düşünülmektedir. ${ }^{27,28}$

Yapılan çalışmalarda, Bis-GMA bazlı rezinlerde TEGDMA oranın artmasının su emilim miktarını arttırdığı, bu durumun artmış yüzey hidrofilikliğine bağlı olduğu belirtilmektedir. ${ }^{29-31}$

Rezin bazlı kompozitlerin matriks içerisine ya da doldurucu-matriks yüzeyine su penetrasyonuna izin verdiği gösterilmiştir. ${ }^{32}$ Rezin içeriğinin materyal renkleşmesinde ana kaynak olduğu, yüksek hacimli rezin içeriğinin renkleşmeyi arttırdığı belirtilmektedir. ${ }^{33}$ Bunun yanında Dietschi ve arkadaşlarının yaptığı çalışmada doldurucu ve rezin oranları arasındaki küçük

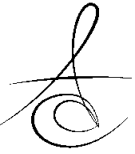


farklılıkların su emilim miktarlarını etkilemediği belirtilmektedir. ${ }^{34}$ Patel ve arkadaşları ise doldurucusuz rezinler ve rezin bazlı kompozitlerin renkleşme miktarlarını inceledikleri çalışmada; doldururucusuz rezinlerin daha fazla rezin matriksine sahip olmalarına rağmen rezin bazlı kompozitlere göre daha az renkleşme gösterdiklerini rapor etmiştir. ${ }^{35}$

Büyük dolduruculu partiküller, yüzey pürüzlülüguünü arttırmakta ve daha fazla renkleşmeye sebep olmaktadır. Doldurucu partikül boyutları küçüldükçe yüzey pürüzlülüğü azalarak renkleşmeye direnç artmaktadır. ${ }^{36}$ Yapılan çalışmalarda nano kompozit materyallerin mikrohibrit ve hibrit kompozitlere göre daha az renkleşme oluşturdukları belirtilmiştir. Rezin bazlı kompozitlerde kullanılan rezinin tipi gibi doldurucu partiküllerin silanlanması da renkleşmede önemli bir faktördür. $\mathrm{Bu}$ da silanın büyük miktarlarda su emilimine bağlıdır. 37,38

Materyale ait doldurucu partikülün karakteristiğinin yanında bitirme ve cilalama işlemleri de yüzey pürüzlülüğünü ve renklendirici pigment tutulumunu direkt olarak etkilemektedir. ${ }^{18,35}$ Materyal yüzeyinin aşınması ve kimyasal bozunması sebebiyle oluşan pürüzlülük ekstrensek faktörlerin renkleştirici etkisini arttırmaktadır. Diş rengi restorasyonların estetik görünümlerini uzun süre devam ettirebilmeleri için yüksek kalitede bitirme ve cilalama teknikleri uygulanarak yüzey pürüzlülüğü azaltılabilmekte ve böylelikle hem plak birikimi hem de restorasyon renklenmesi önlenebilmektedir. ${ }^{18}$

\section{Bireye ait özellikler}

Vogel tarafından yapılan çalışmada, pelikıl ve bakteriyel plak varlığının renkleşmede etkili olduğu rapor edilmiştir. ${ }^{39}$ Erikson ve Nordbö'ya göre ekstrensek etkenlerin renkleşme oluşturması üç mekanizma ile oluşmaktadır. Bunlar; kromojen bakteriler tarafından dental plak içerisinde renkli pigment üretimi, beslenme ile alınan renklendirici gıdaların tutulumu ve pelikıl içeriğinden kimyasal değişim ile renklendirici yapıların üretimi şeklindedir. ${ }^{40}$ Rezin kompozitlerin renkleşmesi üzerine yapılan birçok araştırmada kullanılan içeceklerin oluşturduğu renk değişiminin süre ile arttığı tespit edilmiştir. ${ }^{14,33,41}$

\section{SONUÇ}

Özellikle ön diş estetik restorasyonlarda, restorasyonun klinik başarısında en önemli kriterlerden birisi restorasyonun ilk günkü görünümünü korumasıdır. Ağız ortamında rezin kompozitlerin renkleşmeye olan eğilimleri estetik problemler ortaya çıkarmaktadır. Bu amaçla restorasyon materyali seçiminde, seçilecek materyalin polimerizasyon şekli, doldurucu tipi, su emilimi gibi kimyasal ve fiziksel özellikleri yanında hastanın beslenme tipi, oral hijyen alışkanlıkları, sigara kullanımı gibi faktörlerin de değerlendirilmesi ve hastanın materyal renkleşmesi konusunda bilgilendirilip gerekli uyarıların yapılması önerilmektedir.

\section{KAYNAKLAR}

1. Lee I, Chang J, Ferracane J. Slumping resistance and viscoelasticity prior to setting of dental composites. Dent Mater 2008;24:1586-93.

2. Choi MS, Lee YK, Lim BS, Rhee SH, Yang HC. Changes in surface characteristics of dental resin composites after polishing. J Mater Sci Mater Med 2005;16:347-53.

3. Gupta R, Parkash $H$, Shah N, Jain V. A spectrophotometric evaluation of color changes of various tooth colored veneering materials after exposure to commonly consumed beverages. J Indian Prosthodont Soc 2005;5:72-8.

4. Malekipour MR, Sharafi A, Kazemi S, Khazaei S, Shirani F. Comparison of color stability of a composite resin in different color media. Dent Res J (Isfahan) 2012;9:441-6.

5. Okubo SR, Kanawati A, Richards MW, Childress S. Evaluation of visual and instrument shade matching. J Prosthet Dent 1998;80:642-8.

6. Seghi RR, Gritz MD, Kim J. Colorimetric changes in composites resulting from visible-light-initiated polymerization. Dent Mater 1990;6:133-7.

7. Schulze KA, Marshall SJ, Gansky SA, Marshall GW. Color stability and hardness in dental composites after accelerated aging. Dent Mater 2003;19: 6129.

8. Lepri CP, Palma-Dibb RG. Surface roughness and color change of a composite: Influence of beverages and brushing. Dent Mater J 2012; 31: 689-96.

9. Luiz BKM, Quintella CM, Friedrich LA, da Silva EB, Veiga W, Prates LHM, Bertolino JR, Pires ATN. Effect of drinks on the surface properties of dental resin composites. Poly Test 2007;26:855-61. 
10. Yannikakis SA, Zissis AJ, Polyzois GL, Caroni C. Colour stability of provisional resin restorative materials. J Prosthet Dent 1998;80:533-9.

11. Asmussen E, Hansen EK. Surface discoloration of restorative resins in relation to surface softening and oral hygiene. Scand J Dent Res 1986;94: 1747.

12. Bagheri $R$, Burrow MF, Tyas M. Influence of food simulating solutions and surface finish on susceptibility to staining of aesthetic restorative materials. J Dent 2005;33:389-98.

13. Erdemir $U$, Yildız E, Eren MM. Effects of sport drinks on color stability of nanofilled and microhybrid composites after long-term immersion. J Dent 2012;40:e55-63.

14. de Alencar E Silva Leite $M L$, da Cunha Medeiros E Silva FD, Meireles SS, Duarte RM, Andrade AK. The effect of drinks on color stability and surface roughness of nanocomposites. Eur J Dent 2014;8:330-6.

15. Satou N, Khan AM, Matsumae I, Satou J, Shintani $H$. In vitro colour change of composite- based resins. Dent Mater 1989;5:384-7.

16. Ren YF, Feng L, Serban D, Malmstrom HS. Effects of common beverage colorants on color stability of dental composite resins: the utility of a thermocycling stain challenge model in vitro. J Dent 2012;40: e48-56.

17. Passamonti S, Vrhovsek U, Vanzo A, Mattivi F. Fast access of some grape pigments to the brain. J Agric Food Chem 2005;53:7029-34.

18. Reis AF, Giannini M, Lovadino JR, Ambrosano GM. Effects of various finishing systems on the surface roughness and staining susceptibility of packable composite resins. Dent Mater 2003;19:12-8.

19. Azer SS, Hague AL, Johnston WM. Effect of bleaching on tooth discolouration from food colourant in vitro. J Dent 2011;39: e52-6.

20. Guler AU, Yilmaz F, Kulunk T, Guler E, Kurt S. Effects of different drinks on stainability of resin composite provisional restorative materials. J Prosthet Dent 2005;94:118-24.

21. Vichi A, Ferrari M, Davidson CL. Color and opacity variations in three different resin-based composite products after water aging. Dent Mater 2004; 20 : 530-4.
22. Janda R, Roulet JF, Kaminsky M, Steffin G, Latta M. Color stability of resin matrix restorative materials as a function of the method of light activation. Eur J Oral Sci 2004;112:280-5.

23. Fontes ST, Fernández MR, de Moura CM, Meireles SS. Color stability of a nano-fill composite: Effect of different immersion media. J Appl Oral Sci 2009;17:388-91.

24. Asmussen E. Factors affecting the colour stability of restorative resins. Acta Odontol Scand 1983;41:11-8.

25. Samra AP, Pereira SK, Delgado LC, Borges CP. Color stability evaluation of aesthetic restorative materials. Braz Oral Res. 2008; 22: 205-10.

26. Mair LH. Staining of in vivo subsurface degradation in dental composites with silver nitrate. J Dent Res 1991;70:215-20.

27. Douglas $\mathrm{WH}$, Craig RG. Resistance to extrinsic stains by hydrophobic composite resin systems. J Dent Res 1982;61:41-3.

28. Khan Z, von Fraunhofer JA, Razavi R. The staining characteristics, transverse strength and microhardness of a visible light cured tenture base material. J Prosthet Dent 1987;57:384-6.

29. Kalachandra S, Turner DT. Water sorption of polymethacrylate networks: Bis-GMA/TEGDMA copolymers. J Biomed Mater Res 1987;21:329-38.

30. Mazato S, Tarumi H, Kato S, Ebisu S. Water sorption and colour stability of composites containing the antibacterial monomer MDPB. J Dent 1999;27:279-83.

31. Arima T, Hamada T, McCabe JF. The effects of cross-linking agents on some properties of HEMAbased resins. J Dent Res 1995;74:1597-601.

32. Oysaed $H$, Ruyter IE. Water sorption and filler characteristic of composites for use in posterior teeth. J Dent Res 1986;65:1315-8.

33. Al-Samadani $\mathrm{KH}$. Color stability of restorative materials in response to Arabic coffee, Turkish coffee and Nescafe. J Contemp Dent Pract 2013:14:681-90.

34. Dietschi D, Campanile G, Holz J, Meyer JM. Comparison of the colour stability of ten newgeneration composites: An in vitro study. Dent Mater 1994;10:353-62. 
35. Patel SB, Gordan VV, Barrett AA, Shen C. The effect of surface finishing and storage solutions on the colour stability of resin-based composites. ] Am Dent Assoc 2004;135:587-94.

36. Maalhagh-Fard A, Wagner WC, Pink FE, Neme AM. Evaluation of surface finish and polish of eight provisional restorative materials using acrylic bur and abrasive disc with and without pumice. Oper Dent 2003;28:734-9.

37. Topcu FT, Sahinkesen G, Yamanel K, Erdemir U, Oktay EA, Ersahan S. Influence of different drinks on the colour stability of dental resin composites. Eur J Dent 2009;3:50-6.

38. Güler $E$, Gönülol N, Yücel AC, Yilmaz F, Ersöz E. Farklı içeceklerde bekletilen kompozit rezinlerin renk stabilitelerinin karşılaştırılması. Atatürk Üniv Diş Hek Fak Derg 2013;21:24-9.

39. Vogel RI. Intrinsic and extrinsic discoloration of the dentition : A literature review. J Oral Med 1975;30:99-104.

40. Eriksen HM, Nordbö H. Extrinsic discoloration of teeth. J Clin Peridontol 1978;5:229-36.

41. Villalta $P$, Lu H, Okte Z, Garcia-Godoy F, Powers JM. Effects of staining and bleaching on colour change of dental composite resins. J Prosthet Dent 2006;95:137-42.

\section{Yazışma Adresi}

Arş. Gör. Dt. Başak Bölükbaşı

İzmir Kâtip Çelebi Üniversitesi Diş Hekimliği

Fakültesi Pedodonti AD

Aydınlık Evler Mahallesi, Cemil Meriç Caddesi, 6780 Sokak. No:48, 35640-Çiğli / İZMİR

Tel: +90 (232) 3254040

Fax: +90 (232) 3252535

E-mail: basakbolukbasi@hotmail.com 